\title{
The stability of learners' choices for real-life situations to be used in mathematics
}

Cyril Julie

One of the efforts to improve and enhance the performance and achievement in mathematics of learners is the incorporation of life-related contexts in mathematics teaching and assessments. These contexts are normally, with good reasons, decided upon by curriculum makers, textbook authors, teachers and constructors of examinations and tests. However, little or no consideration is given to whether students prefer and find these real-life situations interesting. There is also a dearth of studies dealing explicitly with the real-life situations learners prefer to deal with in mathematics. This issue was investigated and data on students' choices for contextual issues to be used in mathematics were collected at two time periods. The results indicate that learners' preferences for contextual situations to be used in mathematics remained fairly stable. It is concluded that real-life issues that learners highly prefer are not normally included in the school mathematics curriculum and that there is a need for a multidisciplinary approach to develop mathematical activities which take into account the expressed preferences of learners.

Keywords: school mathematics; real-life situations; learner preferences

\section{Introduction}

In most countries mathematical modelling and the applications of mathematics are currently established components of school mathematics curricula. Various motivations are offered for this development. One of these reasons revolves around the notion of that the interest learners have for mathematics might be enhanced if they experience the use of mathematics in real-life situations. Furthermore, it is proffered that the increase in interest might result in the enhancement of achievement scores of learners. This has led to an increasing emphasis being placed on the applications of mathematics in real-life situations in school mathematics curricula [1] and in international comparative tests such as Trends In Mathematics and Science Study (TIMSS) [2] and the Programme for International Student Assessment (PISA) [3]. Real-life situations in mathematics are extra-mathematical situations defined as 'textual descriptions of situations assumed to be comprehensible to the reader, within which mathematical questions can be contextualized' [4, p. v]. This definition includes the well-known contextualization of mathematics as word problems. 
Students, however, do not necessarily emotionally attach to the contextual situations they are confronted with in mathematics. This means that the real-life situations might not be those which learners have an interest in. In describing an applications-driven school mathematics programme Lesch [5, p. 17], for example, brings this to the fore by asserting that '[teachers'] ideas about the real world were somewhat different from our students' ideas'. Choike [6] also refers to a classroom incident where a 9th grade girl completely detached from engagement with a mathematical problem dealing with sheep farming but when the context was changed to horticulture, an interest of the girl, her attitude towards the problem situation changed to one of active engagement. The differential preferences is also evident amongst prospective teachers. Lingefjard [7, p. 111] reports that prospective teachers ranked contextual situations related to the use of medicine the highest because they found 'models in medicine are "real" in some overall sense and that fact seems to have given the modelling process some extra energy for many students'.

Not only is it that learners and students might not find contexts personally relevant. Teachers also have preferences for contextual situations to be used in mathematics. Zevenbergen et al. [8], for example, found that a group of indigenous Australian teachers did not find the context of a seeming police identification parade suitable and appropriate as inspiration for an open-ended mathematical activity that dealt with averages. Another Australian study indicated that Australian teachers seem to prefer contextual situations of which the mathematical content is clearly visible [9].

The above exemplifies that there might be differences between the real-life situations that appear in learning resources and those learners prefer to deal with. This article reports on an investigation into the 'real-life situations' that learners would prefer to deal with in school mathematics. A major motivation for the investigation was the paucity of studies explicitly addressing the real-life situations learners would prefer to deal with in mathematics. Julie and Mbekwa [10] report on an extensive search of educational research databases, the authoritative Mathematics Education database, MathDi and web-crawling regarding the preferences learners have in real-life situations. They report that studies related to the use of contextual situations in mathematics addressed issues such as the use of contexts for concept- formation [11], the effect of the use of context on learners' mathematical achievement [12] and the ability of learners to identify mathematics in everyday activities [13]. The study reported in this article particularly focuses on whether the hierarchical order preferences learners in grades 8 and 9 expressed for contextual situations to be used in mathematics remained stable or not over two time periods of measurement separated by 4 years. The next section provides a brief description of the development and refinement of the instrument.

\section{Instrumentation and data collection}

The instrument used to ascertain the contextual situations learners preferred to handle in mathematics was developed by mathematics educators from Zimbabwe, 
Uganda, South Africa and Norway and post-graduate students from South Africa, South Korea and Swaziland [10]. One criterion used for the inclusion of items on the instrument was that they should be amenable to mathematical treatment. In this regard literature and textbooks on mathematical modelling, the applications of mathematics and word problems in mathematics were mined to extract real-life situations [10]. The instrument was a questionnaire and learners had to respond by selecting one of four response categories - 'strongly agree', 'agree', 'disagree' and 'strongly disagree'. The initial instrument had 61 items. After piloting and revising the preliminary instrument, data were collected in 2005 in Norway, South Africa, South Korea, Swaziland, Uganda and Zimbabwe. Data were collected from 3964 (1963 boys and 2011 girls) learners in grades 8 to 10 in the six countries. The data obtained from this cohort of learners were analysed and one of the results was that the instrument contained redundant items [14]. The instrument was shortened by replacing groups of conceptually-linked items with a single item. This process rendered a 23-item instrument. The responses the learners in grades 8 and 9 gave to this 23-item instrument were used as the data for the 2005 cohort of learners. For the 2008 learner cohort of grades 8 and 9 data were collected during the second half of 2008 using the revised instrument. The demographic information of the two cohorts of learners is presented in Table 1.

Table 1. Demographic information of the two learner cohorts.

\begin{tabular}{llcc}
\hline & & 2005 & 2008 \\
\hline Gender & Girl & 347 & 202 \\
& Boy & 405 & 186 \\
Grade & Grade 8 & 252 & 218 \\
& Grade 9 & 500 & 170 \\
Average age (years) & & 14.39 & 15.18 \\
\hline
\end{tabular}

Grades 8 and 9 were selected because of the structure of the school system in South Africa. These are the final grades for compulsory schooling. Grade 8 is the first year of high school (grades 8 to 12) and grade 9 is the final year of the General Education and Training (GET) phase of schooling after which they select to study Mathematics or Mathematical Literacy in grades 10 to 12. This selection is highly influenced by their performance in the mathematics examination in grade 9. The schools were in economically and socially depressed areas in the Cape Peninsula area of the Western Cape province in South Africa and it can be safely assumed that the majority of learners were from low socio-economic status (LSES) households.

\section{Data analysis procedure}

The assessment of the preferences of two cohorts of learners at different time periods requires the use of techniques that allow such a comparison. Rasch procedures were 
selected. They are techniques which 'construct linear measures from ordinal observations' [15, p. 338] and defines a 'latent trait in the same manner from time point to time point [which] allows researchers to confidently compare results over time' [16, p. 255]. The Rasch model is a probabilistic model and is described as: a normative model for constructing interval-level unidimensionality of data on a group of subjects for a set of items they have completed. The placement of items on a line that indicates greater and lesser amounts of the variable being measured constitutes operationalisation of the variable. The Rasch model defines the ideal delineation of items that would constitute an objective, interval-level measuring instrument [17, pp. 95-96].

This model is taken as the ideal and it is determined how closely the empirical data fit it. Therefore given that there is an ideal model, data collected at different time periods are always compared to the same model. The Rasch model for polytomous data was used for the analysing the data collected for the research reported here and the suite of programs, Winsteps 3.65.0 [15] was used.

\section{Results and discussion}

Rasch procedures were used to identify misfitting respondents for both sets of data. These are respondents who are identified as responding idiosyncratically by, for example, responding with the same category response for all the items or by responding to a few items and leaving the others blank. The misfitting persons were removed and the demographic information given in Table 1 contains no misfitting respondents.

Analysis of items along gender, grade and time (years) lines were done. This was done to ascertain whether there was differential functioning of items along these dimensions. It was deemed that such differential functioning would compromise the objective of the research embarked upon especially given that boys and girls might have different preferences for real-life situations to be used in Mathematics. The analysis rendered that there was no differential item functioning. This bolsters the use of the instrument because of the non-violation of possible discrimination along the mentioned dimensions.

The ranking of the items are presented in Table 2. The measure is the calibrated value of an item resulting from the logs-odd transformation executed by Rasch modelling. It presents the level of endorsement assigned to the items by the respondents. The item that is easiest to endorse has the lowest measure and vice-versa for the one that is hardest to endorse. Table 2, for example, indicates that the 2005-cohort found item $\mathrm{C}_{4}$ - Mathematics dealing with secret codes such as those for PIN codes in electronic transactions - as the most preferred real-life situation they want to deal with whilst the 2008-cohort most preferred contextual situation is C10 - Mathematics dealing with computer games and storage video and music on discs. The real-life situation 
both cohorts expressed the least preference for is $\mathrm{C} 1$ - Mathematics dealing with lotteries and gambling.

It is also clear that some of the items shifted their ranking positions from 2005 to 2008. These preferences are thus not invariant with respect to their ranking positions. They are provisional and can change dependent upon conditions and developments prevalent at particular historical moments. However, to consider the stability or not of the preferences it is more useful to group real-life situations into zones of preference and assess changes or not between the zones. A model to depict such zones can be developed and hypothesized by 'using [relevant] literature... to map out in broad terms the conceptual and theoretical territory' [18, p. iv]. For this study the literature was mined with the particular focus on how learners and teachers rank contexts used in mathematics and considered views expressed by mathematics educators about the desirability or not for using particular life-related situations in school mathematics. 
Table 2. Measures and ranking of real-life situations.

\begin{tabular}{|c|c|c|c|c|}
\hline Item & Real-life issue & $\begin{array}{l}2005 \\
\text { Measure }\end{array}$ & Item & $\begin{array}{l}2008 \\
\text { Measure }\end{array}$ \\
\hline $\mathrm{C}_{4}$ & Coding of information for security & -0.72 & C10 & -0.44 \\
\hline $\mathrm{C} 17$ & $\begin{array}{l}\text { Personal and business financial } \\
\text { affairs }\end{array}$ & $1-0.51$ & $\mathrm{C} 17$ & -0.24 \\
\hline $\mathrm{C} 10$ & $\begin{array}{l}\text { Construction of computer games } \\
\text { and storage of music and videos on } \\
\text { discs }\end{array}$ & & $\mathrm{C}_{4}$ & -0.23 \\
\hline $\mathrm{C} 16$ & Transmission of electronic messages & s-0.46 & $\mathrm{C} 8$ & -0.21 \\
\hline C19 & $\begin{array}{l}\text { Responding to emergencies and } \\
\text { disasters }\end{array}$ & $d-0.31$ & $\mathrm{C} 23$ & -0.21 \\
\hline C8 & Levels of community development & -0.24 & $\mathrm{C}_{7}$ & -0.21 \\
\hline $\mathrm{C} 18$ & $\begin{array}{l}\text { Recreation, physical exercise and } \\
\text { sport }\end{array}$ & d-0.23 & $\mathrm{C} 6$ & -0.2 \\
\hline $\mathrm{C}_{7}$ & Health matters & -0.16 & $\mathrm{C}_{3}$ & -0.19 \\
\hline $\mathrm{C} 13$ & Pop music & -0.13 & $\mathrm{C} 9$ & -0.17 \\
\hline $\mathrm{C} 2 \mathrm{O}$ & Spread and decline of epidemics & -0.12 & $\mathrm{C} 16$ & -0.12 \\
\hline $\mathrm{C} 12$ & Origin and age of the universe & -0.11 & $\mathrm{C} 18$ & -0.08 \\
\hline $\mathrm{C} 21$ & Planning a journey & -0.02 & $\mathrm{C} 21$ & -0.04 \\
\hline $\mathrm{C} 14$ & National and international politics & 0.01 & $\mathrm{C} 15$ & 0.01 \\
\hline $\mathrm{C} 15$ & Modern youth dances & 0.03 & $\mathrm{C} 12$ & 0.04 \\
\hline $\mathrm{C} 22$ & $\begin{array}{l}\text { Crime fighting, warfare and military } \\
\text { matters }\end{array}$ & yo.15 & $\mathrm{C} 2 \mathrm{O}$ & 0.06 \\
\hline C9 & Productivity & 0.21 & $\mathrm{C} 19$ & 0.07 \\
\hline $\mathrm{C} 23$ & Construction and engineering & 0.26 & $\mathrm{C} 13$ & 0.1 \\
\hline C6 & Government financial matters & 0.27 & C11 & 0.18 \\
\hline $\mathrm{C}_{3}$ & Latest designer clothes & 0.29 & $\mathrm{C} 22$ & 0.26 \\
\hline C11 & $\begin{array}{l}\text { Environmental issues and climate } \\
\text { change }\end{array}$ & eo.31 & $\mathrm{C} 2$ & 0.3 \\
\hline $\mathrm{C}_{2}$ & Cultural products & 0.52 & $\mathrm{C} 14$ & 0.36 \\
\hline $\mathrm{C}_{5}$ & Agriculture & 0.67 & $\mathrm{C}_{5}$ & 0.44 \\
\hline $\mathrm{C} 1$ & Lotteries and gambling & 0.78 & $\mathrm{C} 1$ & 0.52 \\
\hline \multicolumn{2}{|c|}{ Mean } & $\mathrm{o}$ & Mean & $\mathrm{o}$ \\
\hline \multicolumn{2}{|l|}{$\mathrm{SD}$} & 0.38 & SD & 0.24 \\
\hline
\end{tabular}

The literature [7,9,10,14,19-21] renders that learners and teachers highly prefer contexts dealing with modern day communication technologies, modern technological gadgets used for information storage and security related to electronic transactions. Furthermore, fairly high preference was given to real-life situations related to finance and high status professions such as the engineering profession. Issues that are accorded low preference are those that were perceived as being of a non-mathematical nature, having the potential to lead to negative consequences, agricultural matters and practices related to traditional crafts. In addition there were 
situations which had a middle-range preference. These were related to wellness, matters related to the earth/universe, politics and those related to being competent and productive citizens.

These considerations suggest a reasonable model of zones of preference to assess whether changes for preferences for real-life situations to be used in school mathematics. Such a model is presented in Figure 1. The zones are pivoted around the standard deviation of the measures given in Table 2. They are below and above the mean with the standard deviation being the cut-off point for the zones and four zones are identified as indicated in Figure 1.

The model takes into account possible transitions from one zone to another as indicated in the figure.

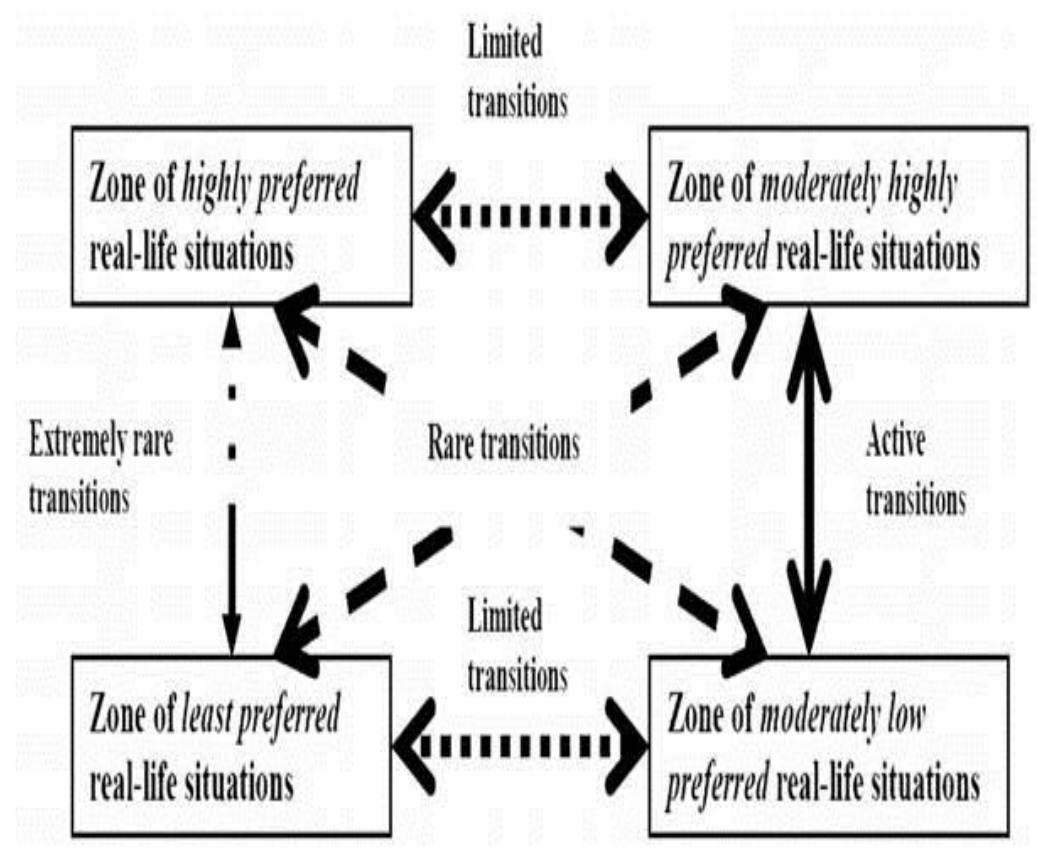

Figure 1. Model for zones of preferences for real-life situations to be used in Mathematics. 


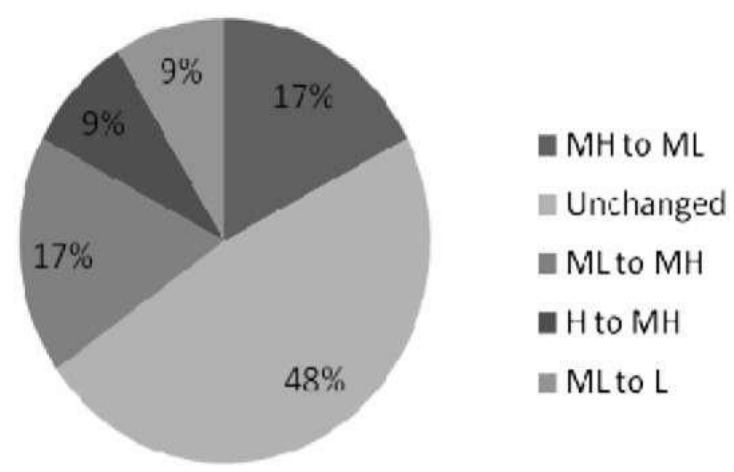

Figure 2. Percentage change in item placement zones.

In general the items behaved as postulated by the model presented in Figure 1. Figure 2 indicate the percentages of items that changed their placement in zones from the 2005 to 2008 cohort.

The active transitions occurred between the moderately high zone and the moderately low one. Forty eight percent of the items did not change their placement. Four items (C12, $\mathrm{C}_{13}, \mathrm{C} 19$ and $\mathrm{C} 20$ ) moved from the moderately high zone to the moderately low one. Seventeen percent of the items transitioned from moderately high to moderately low and a similar 17\% (C3, C6, C9 and C23) from moderately low to moderately high. Two items (C14 and C22) changed from the moderately low zone to the low one and a similar 9\% (C4 and $\mathrm{C} 16)$ transitioned from high to moderately high.

Given the above, it is a reasonable conclusion that the preferences for real-life situations to be used in school mathematics remained fairly stable across the two cohorts of learners.

\section{Conclusion}

The turn to context-driven mathematics characterized by an emphasis on word problems, mathematical applications and mathematical models necessitated the increased use of contextual situations. It is argued that the contextual situations used in school mathematics are not always those which learners would prefer to deal with. It has been shown above that learners do have preferences for contexts and that these preferences are relatively stable. An implication of this is that there is opportunity to include mathematical topics in the school mathematics curriculum which are currently not in the curriculum. Mathematical topics such as queuing theory to deal with electronic communications and coding theory to deal with security during electronic transactions are but two topics which can be introduced given the high preference learners express for such topics. It, however, does not mean that real-life situations for which learners express a low preference should be ignored. Rather, it is also expedient to use such contexts in such a way that learners are inspired to see the empowerment value of mathematically dealing with such situations.

A further implication is that the development of learning resources for dealing with contextual situations in school mathematics cannot be solely left to the current 
designers comprising primarily teachers and project workers. Multidisciplinary teams which include experts from the disciplinary fields dealing with the life-related issues that learners prefer are needed. For example, the moderately high preference accorded to issues related to community development (C8) indicates the need for experts in the development of indexes, mostly econometricians and operational researchers, to partner other school mathematics learning material developers to ensure that the demands of mathematical integrity and the use of relevant contexts are met.

\section{Acknowledgements}

This research is supported by the National Research Foundation under Grant number FA2006042600032. Any opinions, findings and conclusions or recommendations expressed in this material are those of the author and do not necessarily reflect the views the National Research Foundation. 


\section{References}

[1] Department of Basic Education, Curriculum and Assessment Policy Statement, Grades 1012: Mathematics, Pretoria, South Africa, 2011.

[2] I.V.S. Mullis, M.O. Martin, E.J. Gonzalez, and S.J. Chrostowski, TIMSS 2003 International Mathematics Report: Findings From IEA's Trends in International Mathematics and Science Study at the Fourth and Eighth Grades, TIMSS \& PIRLS International Study Center, Chestnut Hill, MA, 2004.

[3] Organisation for Economic Co-operation and Development (O.E.C.D.), Problem Solving for Tomorrow's World: First Measures of Cross-curricular Competencies from PISA 2003, OECD Publications, Paris, 2004.

[4] L. Verschaffel, B. Greer, and E. de Corte, Making Sense of Word Problems, Swets and Zeitlinger, Lisse, 2000

R. Lesh, Applications: Which, why, how? in Applications in School Mathematics, S. Sharon and R.E. Reys, eds., National Council of Teachers of Mathematics, Reston, VA, 1980, pp. 8-19.

[4] J.R. Choike, Teaching strategies for "algebra for all", Math. Teach. 93(7) (2000), pp. 556-560.

[5] T. Lingefjard, Faces of mathematical modeling, ZDM: Int. J. Math. Educ. 38 (2006), pp. 96-112.

[6] R. Zevenbergen, P. Sullivan, and J. Mousley, Contexts in mathematics education: Help? Hindrance? For whom? in Proceedings of the 3rd International MES Conference, P. Valero and O. Skovsmose, eds., Centre for Research in Learning Mathematics, Copenhagen, 2002, pp. 1-9.

[7] R. Pierce and K. Stacey, Enhancing the image of mathematics by association with simple pleasures from real world contexts, ZDM: Int. J. Math. Educ. 38 (2006), pp. 214-225.

[8] C. Julie and M. Mbekwa, What would Grade 8 to 10 learners prefer as context for mathematical literacy? The case of Masilakele Secondary School, Perspect Educ. 23(3) (2005), pp. 31-43.

[9] C. Dapueto and L. Parenti, Contributions and obstacles of contexts in the development of mathematical knowledge, Educ. Stud. Math. 39(1-3) (1999), pp. 1-21.

[10] D. de Bock, L. Verschaffel, D. Janssens, W. van Dooren, and K. Claes, Do realistic contexts and graphical representations always have a beneficial impact on students' performance? Negative evidence from a study on modeling non-linear geometry problems, Learn. Instruct. 13(4) (2003), pp. 441-463.

[11] E. Edwards and K. Ruthven, Young people's perceptions of the mathematics involved in everyday activities, Educ. Research J. 45(3 Winter) (2003), pp. 249-260.

[12] C. Julie and L. Holtman, The Relevance Of School Mathematics Education (ROSME), in Some Developments in Research in Science and Mathematics in Sub-Saharan Africa: Access, Relevance, Learning, Curriculum Research, L. 
Holtman, C. Julie, O. Mikalsen, D. Mtetwa, and M. Ogunniyi, eds., African Minds, Somerset West, 2008, pp. 379-399.

[13]J.M. Linacre, A User's Guide to Winsteps/Ministep Rasch Model Computer Programs, MESA Press, Chicago, IL, 2008.

[14]J.B. Boone and K. Scantlebury, The role of rasch analysis when conducting science education research utilizing multiple-choice tests, Sci. Educ. 90 (2005), pp. 253-269.

[15]Y. de Roos and P. Allen-Meares, Application of Rasch Analysis: Exploring Differences in Depression Between African-American and White Children, J. Soc. Serv. Res. 23 (1998), pp. 93-107.

[16] R. Pawson, Evidence-based Policy: A Realist Perspective, Sage, London, 2006.

${ }_{[17]}$ C. Julie, The context learners prefer for mathematical literacy and their link to present-day issues in South Africa, in Mathematical Modelling: Education, Engineering and Economics, C. Haines, P. Galbraith, W. Blum, and S. Khan, eds., Horwood, Chichester, 2007, pp. 195-202.

[18] C. Julie, Appropriate contexts for teacher in-service courses: Perspectives of practising teachers, S. Afr. J. High. Educ. 23(1) (2009), pp. 113-126.

[19] G. Kaiser-Messmer, Results of an empirical study into gender differences in attitudes towards Mathematics, Educ. Stud. Math. 25 (1993), pp. 209-233. 